\title{
Dual axis solar angle tracking system without any sensor
}

\author{
Zuhal Er \\ Istanbul Technical University, Physics Engineering Department (13b), Maslak-Istanbul, TURKEY, \\ erzuh@itu.edu.tr, ORCID: 0000-0002-9737-1435 \\ Elif Balci \\ Istanbul Technical University, Physics Engineering Department (13b), Maslak-Istanbul, TURKEY, \\ zuhaler@yahoo.com.tr, ORCID: 0000-0003-0158-3255
}

\author{
Arrived: 31.08.2018 Accepted: 21.09.2018 Published: 30.09.2018
}

\begin{abstract}
Owing to swift and irrepressible increase in globalization, the power requirement and energy utilization are also increasing day by day. To compensate the power needs, various renewable energy sources which consist solar energy systems are been used in order to satisfy this ample demand. In order to eliminate the efficiency limits of photovoltaic panel in a solar energy system, there are several methods by solar tracking. In this study, a dual axis solar tracker system is newly designed and tested at several times to track the sun position. A new approach to solar panel systems has been investigated and designed in this study via motivation of no sensor and less mechanical construction. Since a fixed solar panel will not work with the highest solar radiation at every moment of a day; a mobile system which has solar tracker can consider that it will work more efficiently. Owing to the restricted solar radiation reception of fixed panel systems for, a new fabricatemore efficient solar panel has been designed. Photovoltaic tracking mechanism having two axes has been constructed and fabricated. The parts of the system have selected carefully via the multi decision criteria and boundary conditions of the system has settled by calculating solar angles. This paper presents the mentioned design construction detail and -however there is no any sensor- working results of the tracker whereby the movement of a PV panel was controlled to setting of programming of a programmable logic-controller (PLC). To perform the technical task, all electronic circuits and necessary software have been designed and developed with some opportunities in industry and Istanbul Technical University. Fabricated this new design tracker works very well and it is tested with several experimental studies. The results of the experimental studies represent best performance of the fabricated new design. Due to results, sensibility for vertical axis movement of the system is stated 1 degree via calculation. Based on the obtained results this study can conclude that the fabricated new design for a solar dual axis tracking system offers several advantages concerning the improvement of efficiency.
\end{abstract}

Keywords: Solar tracking, Dual axis tracking, Solar panel, PLC, Solar calculations

Cite this $\quad$ Er, Z., Balci, E. Double axis solar angle tracking system without any sensor. Journal of Energy paperas: $\quad$ Systems 2018; 2(3): 130-139, DOI: $10.30521 / j e s .456606$

(C) 2018 Published by peer-reviewed open access scientific journal, JES at DergiPark (www.dergipark.gov.tr/jes)

\begin{tabular}{|c|c|c|c|}
\hline Nomenclature & & & \\
\hline$\Phi$ & Latitude & Ios & Reverse saturation current for the series resistance \\
\hline$\delta$ & Declination angle & $\mathrm{T}_{\mathrm{R}}$ & Reference temperature $\left({ }^{\circ} \mathrm{C}\right)$ \\
\hline$\Omega$ & Hour angle & $\mathrm{k}_{\mathrm{l}}$ & Short circuit current temperature coefficient at IsG \\
\hline$\Psi$ & Solar zenith angle & ISG & Short circuit current at $25^{\circ} \mathrm{C}$ \\
\hline$\alpha$ & Solar elevation angle & $\mathrm{V}$ & Cell voltage $(\mathrm{V})$ \\
\hline$\gamma$ & Azimuth angle & $q$ & Charge of an electron \\
\hline$\beta$ & Inclination of the panel & A & Diode ideality constant \\
\hline$\theta$ & Angle of incidence & $\mathrm{K}$ & Boltzan's constant \\
\hline$\lambda$ & Solar irradiation in $\mathrm{W} / \mathrm{m}^{2}$ & $\mathrm{~T}$ & The absolute temperature $(\mathrm{K})$ \\
\hline I & Output current of the solar cell in Amp & $\mathrm{R}_{\mathrm{s}}$ & Inherent resistances in series (ohm) \\
\hline $\mathrm{I}_{\mathrm{L}}$ & Light generated current in Amp & $\mathrm{R}_{\text {sh }}$ & Inherent resistances in shunt (ohm) \\
\hline
\end{tabular}




\section{INTRODUCTION}

Photovoltaic (PV) technology is an important technology that can convert solar radiation directly from PV panels to electric energy [1]. Photovoltaic electricity generation is making rapid constructed and operated in electricity grids worldwide. The solar capture technologies such as PV have better performance when the direction of the Sun's rays is normal to its surface. However, this is not always possible due to the continuous apparent movement of the Sun. The output parameters/characteristics of a PV panel are unstable and non-linear, with solar radiation, meteorological conditions, temperatures and electrical loads $[2,3,4]$. To improve the efficiency, the solar panel should be such that it always receives maximum solar irradiance variability at ground level. Effective utilization of solar energy for a PV panel requires tracking of the sun $[5,6,7]$. If the PV system has a tracker unit, operators and/or installers would not need to make more corrections that include manual calculation cases at every second at interested location. Moreover, need to know the optimal tilt angle of a panel is essential issue for energy modelers who are calculating regional or global PV output in a given location or worldwide. Therefore, these pushing factors are cause to improving of the tracer systems. A solar tracker is a device or electronic units for a solar tracker is a device for orienting a PV panel towards the sun. The tracker systems that supply that a continuously align the array into the desired position can be categorized in two categories such as single axis tracker and double axis tracker with respect to construction of a PV panel's rotation axis $[4,8,9,10]$.

Using double-axis solar tracking systems, the position of the sun is followed in East-West direction during a day and North-South direction during seasons. Therefore, in several studies, many different methods such as a Light Dependent Resistor (LDR), phototransistors, and other sensors have been proposed and used to track the position of the sun. The current technology on market can be categorized as active tracer and passive tracer. A common solution for the Sun tracking is that a central pivoting PV cell is carried around this pivot by one or more motors connected to an electronic sensor. The sensors are used for measuring and/or detecting the Sun light and generating a corresponding analog voltage signal into the input of the comparator circuit. On the other hand, the problem with such a design with any sensors is that the sensors have a narrow sensitivity range, troubleshooting difficulties, much more cost and weight when they are built in a circuit. In this respect, the aim of this study is to design a dual axis solar tracking system without any sensor in order to eliminate efficiency limits of PV panel to produce electrical energy from solar energy [1,3, 11-17].

\section{BASICS OF THE SOLAR ENERGY}

The several angle evaluations can make between the Sun radiation insulation on the Earth and the surfaces. These angles vary due to position of the sun. In the other words, as know that the Earth rotates about the Sun, the Sun's position varies depending on the longitude and latitude of the interested location. It is clear that the solar angles will be different for different location during the same period. A critical parameter for installing a PV panel is the tilt angle, since PV panel operation efficiency varies by changing exposure to the Sun radiation $[2,3,18,19]$.

In order to construct a system that generates energy from the solar power, it is crucial to know the properties of the Sun and the physical principle that lies behind the energy transformation occurs in the solar panels. As know that geometry of the Sun -Earth occurs some angles between the sun lights and the concerned surface of the Earth. In order to have maximum output solar power from the PV panel it is essential to know these angles [1, 3, 5, 14, 15, 20]. For performance of PV systems at installation 
site, it is important to determine their optimum design. The first step of optimum design purpose has to be determined the tilt angle of a PV panel due to the Sun light insulation at any latitude for any surface azimuth angle. Some studies are rarely given by researchers for optimum tilt angles for fixed PV systems such as the tilt angle is suggested with latitude $\pm 15^{\circ}$ by Lunde [16], with (latitude +15$) \pm 15^{\circ}$ by Duffie and Beckman [11] and with latitude $\pm 8^{\circ}$ by Lewis $[4,18,19]$.

\subsection{Methodology}

Declination angle changes seasonally and approximate value of declination angle can be calculated with Cooper Equation1 [3, 4]. Where $\mathrm{n}$ is the day of the year with Jan 1 as $\mathrm{n}=1$. To describe the hour angle in the Equation 2, zenith angle can be calculated using by the Equation3. Solar elevation angle can be calculated as the Equation 4. Azimuth angle can be written in the form of other angles such as the Equation 5. The angle between the direct sun radiation that comes to the surface and surface normal is called Angle of incidence which is written in the Equation $6[1,2,3]$.

$$
\begin{gathered}
\delta=-23,45 \times \cos \{0,986 x(n+10,5)\} \\
\omega=360 \circ / 24 h *(\text { Local time }-12) \\
\cos (\psi)=\sin (\varphi) \sin (\delta)+\cos (\delta) \cos (\omega) \\
\alpha=\arcsin [\cos (\delta) \cos (\varphi) \cos (\omega)+\sin (\delta) \sin (\varphi)] \\
\gamma=\arcsin [\cos (\delta) \sin (\omega) / \cos (\alpha)] \\
\theta=\arccos [\cos (\delta) \cos (\varphi-\beta) \cos (\omega)+\sin (\delta) \sin (\varphi-\beta)]
\end{gathered}
$$

By using these literatures' equations estimation of the tilt angle of the solar panel in daily and seasonally basis is done in this study. In this point to have a basic estimation, the values from the solar angle calculator $[1,2,3,11,17-20,21-23]$ are used for calculating tilt angle of the solar panel in a year. The $\beta$ tilt angles are shown in Table 1 .

Table 1. Optimum tilt of solar panels in Istanbul by months

\begin{tabular}{llllll}
\hline January & February & March & April & May & June \\
\hline $33^{\circ}$ & $41^{\circ}$ & $49^{\circ}$ & $57^{\circ}$ & $65^{\circ}$ & $72^{\circ}$ \\
July & August & September & October & November & December \\
$65^{\circ}$ & $57^{\circ}$ & $49^{\circ}$ & $41^{\circ}$ & $33^{\circ}$ & $26^{\circ}$ \\
\hline
\end{tabular}

A photovoltaic cells generate electricity as a consequence of the effect of solar radiation on semiconductors. The electrical energy gained from solar energy can mathematically shown in the Equation 7. where panel reverse saturation current $\mathrm{I}_{\mathrm{os}}$ and current generated by the light $\mathrm{I}_{\mathrm{LG}}$ are given by the Equation 8 and the Equation 9 respectively $[1-3,6-8,18,19,23]$. The values of these parameters depend upon solar irradiance and cell temperature. 


$$
\begin{gathered}
I=I_{L G}-I_{O S}\left\{e^{\left[\frac{q}{A k T}\left(V+I_{L} R_{S}\right)\right]}-1\right\}-\frac{V+I_{L} R_{S}}{R_{S h}} \\
I_{O S}=I_{O R}\left[\frac{T}{T_{R}}\right]^{3} e^{\left[\frac{q E_{G O}}{B k}\left(\frac{1}{T_{R}}-\frac{1}{T}\right)\right]} \\
I_{L G}=\left[I_{S C}+k_{l}(T-25)\right] \lambda
\end{gathered}
$$

where, $I$ is the output current of the solar cell; $I_{L}$ is the current across the $p$-n junction (light generated current which depends upon the solar insolation); Ios is the reverse saturation current for the series resistance; $T_{R}$ is the Reference temperature; $k_{1}$ is the Short circuit current temperature coefficient at $\mathrm{I}_{\mathrm{SG}}$; $\mathrm{I}_{\mathrm{SG}}$ is the Short circuit current at 25 degree Celsius; $\lambda$ is the Solar irradiation in $\mathrm{W} / \mathrm{m}^{2} ; \mathrm{I}_{\mathrm{sc}}$ is the short circuit current $(\mathrm{A})$; $\mathrm{V}$ is cell voltage $(\mathrm{V})$; $\mathrm{q}$ is the charge of an electron equal to $1.6 \times 10-19(\mathrm{C})$; $\mathrm{A}$ is the diode ideality constant; $\mathrm{K}$ is the Boltzan's constant $1.38 \times 10-23(\mathrm{j} / \mathrm{K})$; $\mathrm{T}$ is the absolute temperature (K) of the junction; $R_{\mathrm{s}}$ and $\mathrm{R}_{\mathrm{sh}}$ are the inherent resistances in series and in shunt to the cell associated $[4,20,23]$.

\section{DESIGN and EXPERIMENTAL SETUP}

The solar panel has been designed and the prototype of the system produced related to the motion type of the model. As it is mentioned before, the system has binary motion in order to get the solar radiation perpendicular to the panel's surface every time. The solar panel makes its rotation around its vertical axis in monthly basis. The orientation of the panel in vertical is related to the azimuth angle of the sun that has been described in geometry of the sun part. In addition to that, the solar panel has its rotation around its horizontal axis in daily basis depending on sunrise and sunset times. To find this orientation, required tilt angle has calculated. Illustration about the motion of the designed system has shown below in Figure 1.

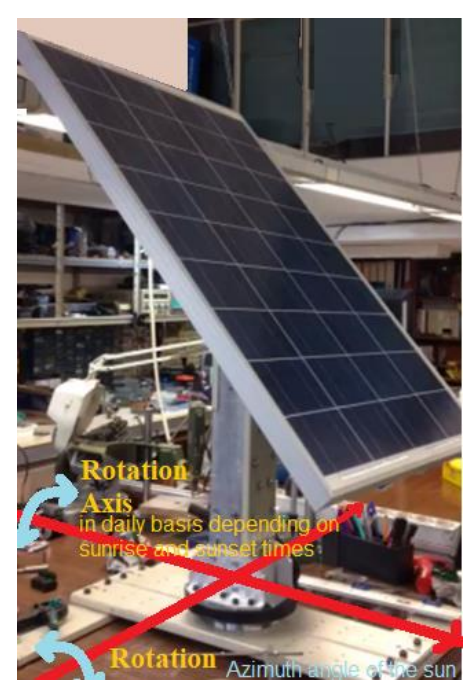

Figure 1. Operation of solar tracking system.

DC motors with reductors used for both axis. The reason why reduction is applied to motors is that the movement speed has to be too slow, since the system follows seasonal, monthly and daily activities of the Sun. Motor that has been used for horizontal motion showed in the Figure 2. 


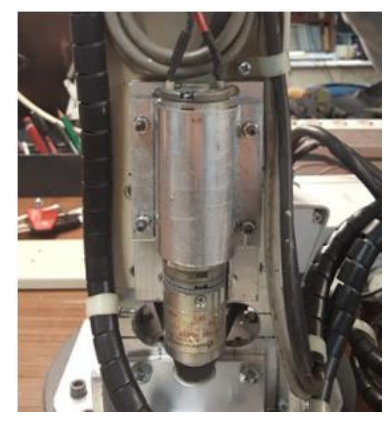

Figure 2. Motor which used for horizontal motion.

Gearwheels are used as reductors. In order to link motors, potentiometers and gearwheels enabling the movement of two axis, belt hoops are used. For both axis, potentiometers are used in order to provide position feedback of the panel. It measures the electric potential corresponding the position of the panel in degrees. By using potentiometers, sensibility of movement for both axis are calculated. The potentiometer used in the system and boundary potentials of the potentiometer is schematically shown in the Figure 3.

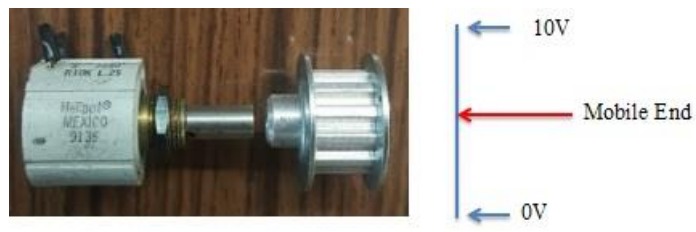

Figure 3. Boundaries and mobile end of potentiometer.

The shaft, shown in the Figure 4, is used for the motion of horizontal axis and transmits linear movement to rotational movement of the panel. It does not lose the position when the motor stops so no break needed. There are 2 limit switches, for both axis and for both sense of rotations (positive and negative) which keep the horizontal movement of the panel staying in defined boundaries.

If the movement cross these boundaries, in undefined region, there exist 2 other limit switches (for both sense) for emergency cases in order to stop the motor. So totally 4 limit switches have used in the mechanism.

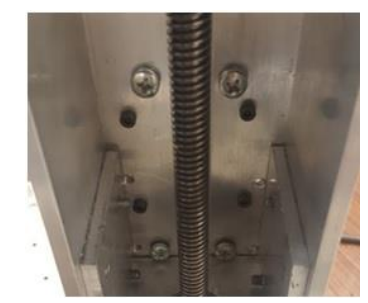

Figure 4. Shaft used for the vertical motion.

The mechanism for the vertical axis of the solar panel system is based on a turning base with ball bearings as it is said before. The base is attached to its motor with a belt hoop so as to apply gearwheel principle and the potentiometer is stated between them. The schematic representation and the design of the mechanism is shown below in the Figure 5. 


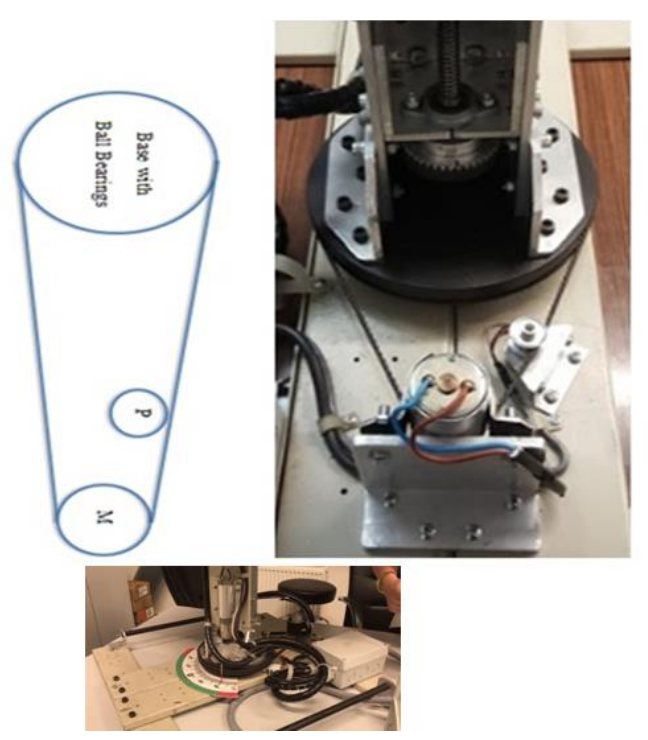

Figure 5. The vertical motion mechanism.

Horizontal axis is designed with motor, a shaft with screw and a horizontal plane on which the panel is fixed. In addition, an equipment like movement crank is put in order to transmit linear movement on the shaft to rotation movement on the panel plane as shown in the Figure 6. There exists a gearwheel mechanism between the motor and the shaft with screw. The geared motor is linked to gear of shaft via belt hoop.
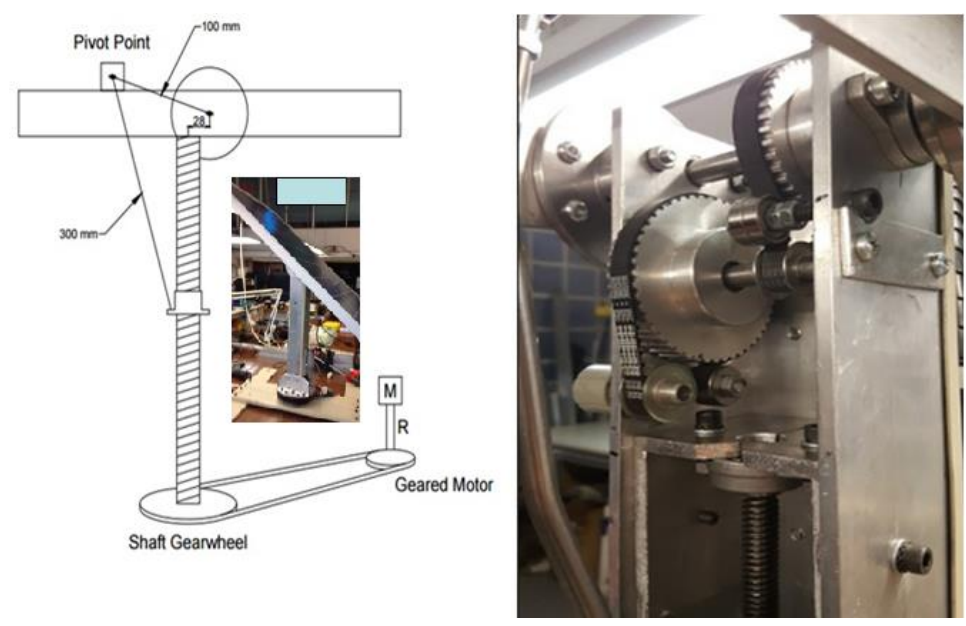

Figure 6. The horizontal motion mechanism.

\section{RESULTS and DISCUSSIONS}

According to gear numbers, rpm (revs per minute) and the reduction of the motor, sensibility for vertical axis movement is calculated. This sensibility is stated 1 degree for both axis. To illustrate, when the system receives a command to turn 5 degrees to positive way, potentiometers give the position feedback to the PLC, but the system will work until the axis turns 5 and \pm 1 degrees. The RPM calculations for vertical axis motor is given by the Table 2 . 
Table 2. Revolutions for vertical motion motor

\begin{tabular}{lllll}
\hline RPM $\left(\mathrm{min}^{-1}\right)$ & Reduction $\left(\mathrm{min}^{-1}\right)$ & $\mathrm{RPM}\left(\mathrm{min}^{-1}\right)$ & $\mathrm{RPS}\left(\mathrm{sec}^{-1}\right)$ & Gear Number \\
\hline 3000 & 120 & 25 & 0,416 & 24 \\
\hline
\end{tabular}

For sensibility calculations, resolution of PLC is taken 1024 bit and the voltage for analog input is $10 \mathrm{~V}$ with resolution of $0,01 \mathrm{mV}$. Base with bear spheres has 125 gears and potentiometers have 10 gears. This gives a 12,5 reduction for potentiometer (when base turns 360 degrees $=1$ cycle, potentiometers makes 12,5 cycles). We want the vertical axis to make 90 degrees, that gives us 3,125 cycles. Calculations are shown in Table 3.

Table 3. Sensibility value for vertical motion motor

\begin{tabular}{lllllll}
\hline \multicolumn{2}{c}{ Gear Number } & \multicolumn{2}{l}{ Potentiometer Reduction } & Resolution & \multicolumn{2}{c}{ Sensibility } \\
\hline Base & 125 & $360^{\circ}$ & 12,5 cycles & 0,0347 & Mechanical & $0,2813^{\circ}$ \\
Potentiometer & 10 & $90^{\circ}$ & 3,125 cycles & & Defined & $1^{\circ}$ \\
\hline
\end{tabular}

The RPM calculations for horizontal axis motor is given by the Table4.

Table 4. Revolutions for horizontal motion motor

\begin{tabular}{lllll}
\hline RPM $\left(\mathrm{min}^{-1}\right)$ & Reduction $\left(\mathrm{min}^{-1}\right)$ & RPM $\left(\mathrm{min}^{-1}\right)$ & RPS $\left(\mathrm{sec}^{-1}\right)$ & Gear Number \\
\hline 3000 & 32 & 93,75 & 1,56 & 10 \\
\hline
\end{tabular}

The rotation movement for vertical axis is constructed with 2 stages of gearwheel mechanism. For the up stage, there exist one gearwheel with 40 gears and a potentiometer with 10 gears, the potentiometer gearwheel is linked to down stage, to the gearwheel with 48 gears and another potentiometer with 12 gears. 1 cycle for upstage means 16 cycles for potentiometer. It is defined 180 degrees for horizontal axis, thus up stage linked to panel should make $1 / 2$ cycle which means 8 cycles for potentiometer. The calculations for horizontal motor are shown in Table5. Therefore, it can underline which the orientation of the panel in vertical with motor control is in line to the azimuth angle of the sun. Also, horizontal motion results of the motor is in line with the daily basis depending on sunrise and sunset times.

Table 5. Sensibility value for horizontal motion motor

\begin{tabular}{llrlllll}
\hline Stages & \multicolumn{2}{c}{ Gear Number } & \multicolumn{2}{c}{ Potentiometer Reduction } & Resolution & \multicolumn{2}{c}{ Sensibility } \\
\hline \multirow{2}{*}{ Up } & Gearwheel & 40 & $360^{\circ}$ & 16 cycles & & Mechanical & 0,2813 \\
& Potentiometer & 10 & & & 0,044 & & \\
Down & Gearwheel & 48 & $180^{\circ}$ & 8 cycles & & Defined & $1^{\circ}$ \\
& Potentiometer & 12 & & & & & \\
\hline
\end{tabular}

Moreover, these results are tested under several calculations and measurements as mentioned above part. As before mentioned, the Sun tracking is set on the solar angle calculations. Therefore, this study has result of calculations of the tilt angles and measured values of the intensity of direct radiation in $\mathrm{W} / \mathrm{m}^{2}$ throughout the day. In this point, the graphical evaluations of the intensity of direct radiation in $\mathrm{W} / \mathrm{m}^{2}$ throughout the day will service comparative view for our results. In the other word, tilt calculations result that are given by the Table 1 in the part of methodology of this study were very successful when they combined the measuring results as shown in the Figure 7. 

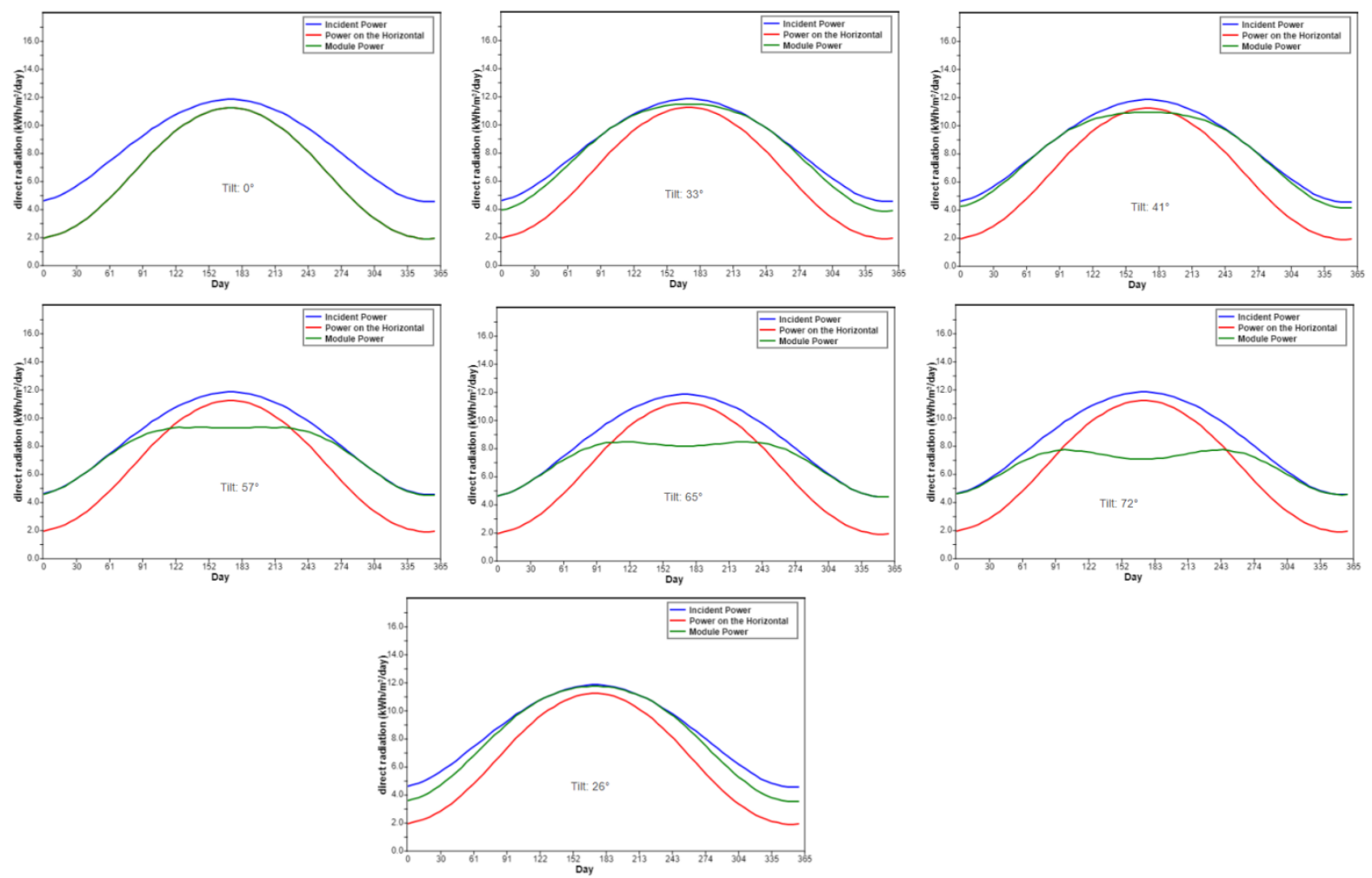

Figure 7. The graphs of the intensity of direct radiation in $\mathrm{W} / \mathrm{m}^{2}$ throughout the day.

Figure 7 represents the good correlations between the calculated tilt angle and measured values for acceptable evaluation for well working of tracker design. It is clear that power varies with tilt angle and solar radiation as mentioned the above parts and our literature reviews [1-23].

In the case of 0-degree tilt variation around an axis parallel to the horizontal plane of PV, a nearly constant direct radiation is observed for the module power and power on the horizon. In this case, the module power with power on the horizon does not change as illustrated on the Figure 7. However, as the graph is also shown as in the Figure7 radiation which is shown in green line quickly decreases for incidence angles larger than $2^{\circ}$ dependents on the module orientation. It is visible from the plot that between the months of April to June, the optimum irradiation is achieved when the tilt angle is at 0 degree. The results show, that the angle under which light hits the PV has a significant impact on its performance. The new designed and structured tracker can therefore function as intended, i.e. detecting the direct radiation, for all angles of incidence. Result from the study shows that, using the tilt angle that yields the optimum irradiation for each month and daily can substantially increase PV energy production.

\section{CONCLUSION}

Compared to other studies on solar tracking systems, double axis sun tracking system in this study has constructed without any sensor so as to gain more output power from photovoltaic module in daily and seasonal basis. The fabricated design without any requirement of sensor usage for the Solar tracking is a novelty of this study. In addition, with the help of control panel, modification of different location option also would be possible. So the system with the same productivity would also be able to use different locations and different sun tracking project. 
Consequently, this study can be used for many applications and also can be developed for different projects related to the position of the Sun or for mechatronics tracking applications. For example, to produce electricity from panel, to charge batteries by using the electricity produced or maybe doing efficiency analysis by doing experimental and comparing them with other fixed/single axis panels.

\section{Limitations of the work}

As a result of limited financial and laboratory resources, the solar radiation tracker could not be continuously investigated with much more equipped analyzing units/ more expensive devices to enable us perform future evaluations.

\section{Acknowledgment}

For the laboratory support, we would like to express our deep appreciation to the Laboratory of Control and Automation in ITU. We sincerely thank all ECRES2018 for oral presentations of our prototype.

\section{REFERENCES}

[1] Balci E, Marangozoglu S. Double Axis Solar Tracking System. Advanced Physics Project Thesis, Istanbul Technical University, Turkey, 2017.

[2] Er, Z. A Study of Evaluation of Solar Energy Simulation and Modeling Systems. Acta Physica Polonica A / 2016; 130(1), 72.DOI: 10.12693/APhysPolA.130.72

[3] Er Z, and Taviloglu S. An Arduino Application Ona Solar Tracking System. In: Proceedings of the Conference 2nd International Conference on Computational and Experimental Science and Engineering, Antalya, 2015, ICCESEN15, No:2412282.

[4] Bezir, NC, Akkurt, I, Ozek, N. The development of a computer program for estimating solar radiation. Energy Sources Part A: Recovery Utilization, and Environmental Effects, 2010. 32(11), 995-1003. doi: $10.1080 / 15567030902937234$

[5] Ozerdem, OC. Design of two experimental setups for programmable logic controller (PLC) laboratory. International Journal of Electrical Engineering Education/ 2016; 53(4),331-340. DOI: $10.1177 / 0020720916630325$

[6] Cubas J, Pindado S, and Manuel d. C. Explicit Expressions for Solar Panel Equivalent Circuit Parameters Based on Analytical Formulation and the Lambert W-Function. Energies /2014; 7, 4098-4115. doi:10.3390/en7074098

[7] Sushma VR, SnehaVM. PLC Based Solar Tracking Panel Assembly. International Journal of Engineering Trends and Technology (IJETT) /2014; 18(5), 230-234.

[8] Prinsloo, G, Dobson, R. Solar Tracking. e-book, solar books, DOI:10.13140/RG.2.1.4265.6329/1

[9] Clifford, MJ, Eastwood, D. Design of a novel passive solar tracker, Solar Energy, Volume 77, Issue 3, September 2004, Pages 269-280, https://doi.org/10.1016/j.solener.2004.06.009

[10] Pandey, A,Dasgupta, N, Mukerjee, AK.High-Performance Algorithms for Drift Avoidance and Fast Tracking in Solar MPPT System. IEEE transactions on energy conversion 2008,23(2), 681-689, DOI: 10.1109/TEC.2007.914201

[11] Duffie JA, Beckman WA. Solar engineering of thermal processes. New York: Wiley, 1982.

[12] Islam, H, Mekhilef, S, Shah, NBM, Soon, TK, Seyedmahmousian, M, Horan, B, Stojcevski, A. Performance Evaluation of Maximum Power Point Tracking Approaches and Photovoltaic Systems. Energies 2018, 11, 365.DOI: https://doi.org/10.3390/en11020365

[13] Bingol, O, Altıntaş, A, Oner, Y. Microcontroller based solar-tracking system and its implementation. Journal of Engineering Sciences 2006, 12 (2), 243-248. 
[14] Ertekin,C, Evrendilek, F, Kulcu, R.. Modeling spatio-temporal dynamics of optimum tilt angles for solar collectors in Turkey. Sensors 2008, 8(5), 2913-2931. DOI: https://doi.org/10.3390/s8052913

[15] Wang, S, Hong, B. Optimum design of tilt angle and horizontal direction of solar collectors under Obstacle's shadow for building applications. Journal of Building Construction and Planning Research 2015, 3, 60-67. DOI: http://dx.doi.org/10.4236/jbcpr.2015.32007

[16] Calabrò, E. An algorithm to determine the optimum tilt angle of a solar panel from global horizontal solar radiation. Journal of Renewable Energy 2013, volume2014, ID 307547, 12 pages. DOI: http://dx.doi.org/10.1155/2013/307547

[17] Idowu, OS, Olarenwaju, OM, Ifedayo, OI. Determination of optimum tilt angles for solar collectors in low-latitude tropical region. International Journal of Energy and Environmental Engineering 2013, 4(29), 10 pages. DOI: http://www.journal-ijeee.com/content/4/1/29

[18] Er, Z. Utilization of the collector rainbow system in Istanbul. Acta Physica Polonica A 2015, 128 (2B), B300-302. DOI: 10.12693/APhysPolA. 128.B-300

[19] Er, Z. A Study of importance of solar calculations for two colored rainbow system in Istanbul. Acta Physica Polonica A2015, 128 (2B), B477-B478. DOI: 10.12693/APhysPolA. 128.B-477

[20] Chikh, A, Chandra, A. An optimal maximum power point tracking algorithm for pv systems with climatic parameters estimation. IEEE Transactions on Sustainable Energy 2015, 6(2), 644-652. DOI: 10.1109/TSTE.2015.2403845

[21] WMO. Guide to Meteorological Instruments and Methods of Observation. World Meteorological Organization, 2008, No 8, ISBN 978-92-63-10008-5

[22] Ernst, M, Holst,H, Winter, M, Altermatt, PP. Sun Calculator: A program to calculate the angular and spectral distribution of direct and diffuse solar radiation. Solar Energy Materials and Solar Cells 2016, 157, 913-922. https://doi.org/10.1016/j.solmat.2016.08.008

[23] Markvart, T, Castaner, L. Practical handbook of photovoltaics fundamentals and applications. Amsterdam: Elsevier, 2003. 